\title{
Katmanlı İmalat ile Üretilen Metal Malzemelerin Kaynak Kabiliyeti
}

\author{
${\text { Kadir } \text { AYDIN }^{1 *} \text {, Mustafa KARAMOLLA }}^{2}$ \\ ${ }^{I}$ Dumlupinar Üniversitesi Simav Meslek Yüksekokulu, Kütahya, Türkiye \\ ${ }^{2}$ Manisa Celal Bayar Üniversitesi Makine Mühendisliği Bölümü, Manisa, Türkiye \\ (ORCID: 0000-0001-5701-8058 (ORCID: 0000-0002-0196-9820 )
}

\section{$\ddot{O} \mathbf{z}$}

Katmanlı imalat teknolojisine olan ilgi son yıllarda artış göstermektedir. Katmanlı imalat tekniği, geleneksel imalat yöntemlerinin aksine malzeme eksiltme değil de, malzeme eklenmesi prensibine dayanmaktadır. Yüksek tasarım serbestliği, artık malzeme oluşmaması, kullanıcıya özel ürünlerin imal edilebilmesi, tasarımdan imalata geçiş süresinin düşük olması, hücresel yapılar ve optimum tasarımlar ile daha hafif ürün elde edilebilmesi katmanlı imalat tekniğinin avantajlarındandır. Bunun yanında katmanlı imalat tekniğinin bir takım dezavantajları da bulunmaktadır. Bunlardan bir tanesi katmanlı imalat ile üretilen ürünlerin boyutlarının sinırlı olmasıdır. Araştırmacılar bu problemi ortadan kaldırmak amacıyla katmanlı imalat tekniği ile üretilen metalik malzemeleri kaynak yöntemiyle birleştirerek çalışmalar yapmaktadır. Bu çalışmada lazer ergitme-sinterleme ve elektron ışını ergitme yöntemleri kullanılarak üretilen malzemelerin kaynak kabiliyetinin araştırıldığı çalışmalar derlenmiştir.

Anahtar kelimeler: Katmanlı imalat, Kaynak, Metal malzemeler.

\section{Welding Capability of Metal Materials Produced by Additive Manufacturing}

\begin{abstract}
The interest in additive manufacturing technology has increased in recent years. The additive manufacturing technique is based on the principle of adding material, not material reduction, as opposed to conventional manufacturing methods. High design freedom, no residual material, the manufacture of user-specific products, the low transition time from design to manufacturing, the ability to obtain lighter products with the cellular structures and optimum designs are among the advantages of the additive manufacturing technique. In addition, there are some disadvantages of the additive manufacturing technique. One of them is the limited size of the products produced by additive manufacturing. In order to eliminate this problem, researchers have been working by joining the metallic materials produced by the additive manufacturing technique with the welding method. In this study, studies on the welding ability of the materials produced by using laser melting-sintering and electron beam melting methods were collected.
\end{abstract}

Keywords: Additive manufacturing, Welding, Metal materials.

\section{Giriş}

Katmanlı imalat; üç boyutlu olarak hazırlanan tasarımları (CAD) birikimli (eklemeli) olarak imal eden üretim tekniği olarak tanımlanmaktadır [1]. Bu üretim yöntemi üç boyutlu üretim, hızlı prototipleme, eklemeli imalat olarak da adlandırılmaktadır [2]. Katmanlı imalat yönteminin medikal, mimari, havacılık ve otomotiv sektöründe kullanım alanı giderek artmaktadır [3]. Katmanlı imalatın işlem basamakları Şekil 1'de verilmiştir. İlk basamakta üretilmesi istenen parçanın 3 boyutlu CAD modeli oluşturulur. İkinci basmakta 3 boyutlu CAD model bir arayüz program vasitasıyla STL dosyasına dönüştürülür. Üçüncü basamakta ise 3 boyutlu fiziksel model dilimlenerek basit bir şekilde gösterilmesi sağlanmaktadır. İmalata hazır olan modelin verisi makineye gönderilir ve eklemeli olarak imalat

*Sorumlu yazarkadir.aydin@dpu.edu.tr

Geliş Tarihi: 10.03.2019, Kabul Tarihi:11.07.2019 
gerçekleştirilir. Son olarak imalatı tamamlanan parça kesici bir cisim vasıtasıyla tezgah tablasından ayrılmaktadır $[4,5]$.

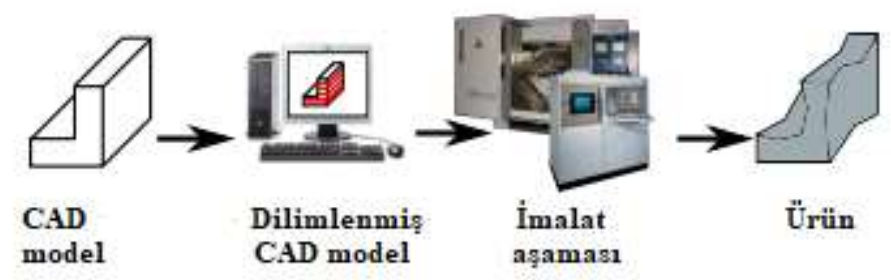

Şekil 1. Katmanlı imalat yönteminin işlem basamakları [6]

Metalik malzemelerin katmanlı imalat tekniği ile üretiminde birç̧ok yöntem geliştirilmiştir. $\mathrm{Bu}$ yöntemler seçici lazer ergitme, seçici lazer sinterleme, elektron ışını ergitme, direk metal biriktirme ve tel ark eklemeli imalat olarak sıralanabilmektedir [7]. Metalik malzemelerin katmanlı imalatı hammadde kullanım tipi ve 1sı kaynağına göre karakterize edilebilmektedir. Hammadde kullanımı toz veya tel şeklinde ayrılırken, ısı kaynağı lazer ışını ve elektron ışını olarak sınıflandırılmaktadır [8-9].

Birçok avantaja sahip olmasından dolayı katmanlı imalat tekniğinin kullanımı son yıllarda artış göstermiştir. Kompleks yapılı parçaların üretilebilmesi, yeni ürünlerin imalatında kalıp yapımına ihtiyaç duyulmaması, tasarım imalat arası sürenin düşük olması, talebe özel ürün oluşturulabilmesi ve artık malzeme oluşmaması bu avantajlardan bazılarıdır [10]. Bunun yanında katmanlı imalat tekniğinin bazı dezavantajları da bulunmaktadır. Bu dezavantajlardan bir tanesi de bu yöntemle üretilen parçaların boyutsal sınırlamalara sahip olmasıdır. Katmanlı imalat tekniği ortalama $0.02 \mathrm{~m}^{3}$ hacminde parçaların üretilebilmesine olanak sağlamaktadır [11]. Bu problemi ortadan kaldırmak amaciyla küçük boyutta üretilen parçalar kaynak yöntemiyle birleştirilerek daha büyük parçalar haline getirilebilmektedir. $\mathrm{Bu}$ çalışmada katmanlı imalat ile üretilen metalik malzemelerin kaynakla birleştirilmesi sonucu mikroyapı ve mekanik özelliklerindeki değişimlerin araştırıldığı çalışmalar derlenmiştir.

\section{Katmanlı İmalat ile Üretilen Malzemelerin Kaynağı}

Literatür araştırmalarından metalik malzemelerin lazer ve elektron 1şını vasıtasıyla ergitilerek veya sinterlenerek elde edildiği tespit edilmiştir. Bu parçaların ancak sınırlı boyutlarda üretilebildiği ve bu nedenle üretilen parçaların kaynak yöntemiyle birleştirilerek daha büyük boyutlar elde edilebileceği anlaşılmıştır. Katmanlı imalat (Kİ) tekniğinin henüz yeni bir üretim tekniği olmasından dolayı bu konuda yapılan araştırmaların yeterli seviyede olmadığı anlaşılmaktadır. Bu çalışmada Kİ metal malzemelerin kaynağı malzeme ergitme tipine göre sınıflandırılıp aşağıda bölümler halinde verilmiştir. Kullanılan katmanlı imalat, malzeme ve kaynak yöntemleri Tablo 1'de verilmiştir.

Tablo1. Kullanılan imalat yöntemi, malzeme ve kaynak prosesleri

\begin{tabular}{ccc}
\hline Katmanlı imalat yöntemi & Malzeme & Kaynak yöntemi \\
\hline SLE & AlSi10Mg & Sürtünme karıştırma kaynağ1 \\
SLE & Al-12Si & Sürtünme kaynağ1 \\
SLE & Lazer kaynağ1 \\
SLE & $18 \mathrm{Ni} 1300$ & Lazer kaynağ1 \\
SLE & 316 & Lazer-ark hibrit kaynağ1 \\
SLE & Ti6Al4V & Sürtünme kaynağ1 \\
SLE & Ti-6.5Al-3.5Mo-1.5Zr-0.3Si & Elektron 1şın kaynağ1 \\
SLE & Inconel625 & Lazer kaynağ1 \\
EIE & Ti6Al4V & Sürtünme karıştırma kaynağ1 \\
EIE & Ti6Al4V & Lazer kaynağ1 \\
EIE & Ti6Al4V & Lineer sürtünme kaynağ1 \\
EIE & Ti-48Al-2Cr-2Nb & Sürtünme kaynağ1 \\
EIE & Ti6Al4V & Yerinde kaynak yöntemi \\
\hline
\end{tabular}




\subsection{Lazer Işını ile Üretilen Malzemelerin Kaynağı}

Lazer ışını ile katmanlı imalat prosesi 1Sı oluşumunu sağlayan lazer ışını vasıtasıyla katman katman parça oluşturulması prensibine dayanmaktadır. Prosesin ilk aşamasında, 1sıtıldığında birbirine bağlantısı gerçekleştirilen toz parçacıklar ince ve düz bir tabaka halinde bir merdane veya bıçak vasıtasıyla üretim tablasının üzerine yayılmaktadır. Lazer ışını, tarayıcı sistem aracılığıyla tabaka halindeki tozlar üzerinde seçilen bölgeleri tarar ve ilk katman tamamlanır. İkinci katmanı inşa etmek için tezgâh tablası altında bulunan platform katman kalınlığı seviyesinde aşağı inmektedir. Sonra tozun yayılmasını sağlayan merdane veya bıçak vasıtasıyla taranmış katmanın üzerine yeni katman kalınlığı kadar toz serilir ve lazer ışını ile tarama gerçekleştirilir. Bu süreç parça oluşuncaya kadar devam etmektedir. Ergitme ve sinterleme operasyonu tamamlandıktan sonra imal edilen parça üretim tablasından çıkarılarak kullanıma hazır hale getirilmektedir [12]. Şekil 2'de lazer ışını ile katmanlı imalat işlem akışı verilmiştir.

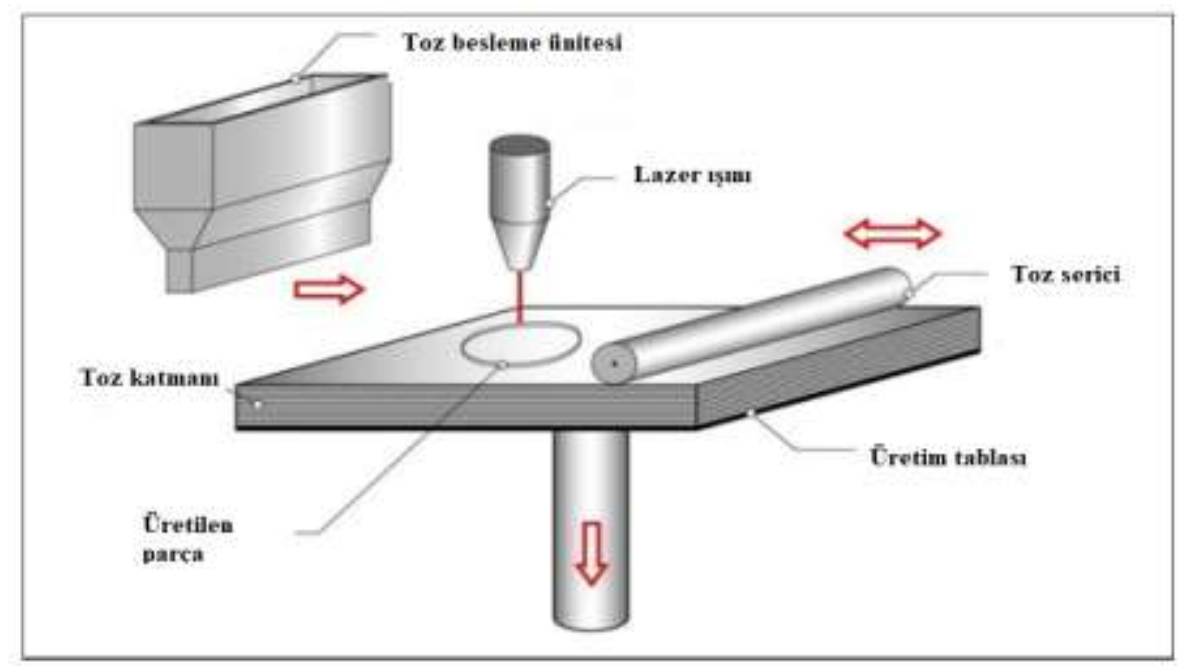

Şekil 2. Lazer ışını ile katmanlı imalat işlem akışı [13]

Lazer ışını ile üretilen parçalar boyutsal sınırlamalara sahiptir. Bu problemi ortadan kaldırmak için üretim platformunu genişletmenin bazı sakıncaları bulunmaktadır. Büyük hacimde parçalar imal edebilmek için birden fazla lazer kaynağı kullanıldığında bu kaynaklar arasında muhtemel kalibrasyon farkı bulunduğu takdirde parçanın mekanik özelliklerinde yerel farklılıklar ortaya çıkabilir. Bir diğer sakınca ise üretim kısmının genişletilmesi halinde köşe kısımlarının lazer odak çapında farklılıklara yol açabilmesidir. Bu sebeplerden dolayı küçük hacimde üretilen lazer ışınlı katmanlı imalat parçaları farklı birleştirme teknikleri kullanılmak suretiyle daha büyük hacimli parçalara dönüştürülebilmektedir [1417].

Katmanlı imalatta gözlemlenen problemlerden birisi de imalat aşamasında uygun parametreler seçilmediği zaman gözenekli yapıların oluşabilme durumudur. Kaynakla birleştirilen katmanlı imalat parçalarında bu durumun nispeten azaldığı tespit edilmiştir. Du ve diğerleri seçici lazer ergitme (SLE) ile üretilmiş $\mathrm{AlSi} 10 \mathrm{Mg}$ ve $\mathrm{AlSi} 10 \mathrm{Mg}-\mathrm{Al}_{2} \mathrm{O}_{3}$ kombinasyonlarını sürtünme karıştırma kaynağ 1 ile birleştirerek mikroyapı ve mekanik özelllikleri incelemişlerdir. Proses sonunda kaynaklı bölgede gözenekli yapıya rastlanmazken, ana metal kısmında ortalama \%9 civarında gözenek yoğunluğu tespit edilmiştir. Ayrıca kaynaklı bölgede dinamik yeniden kristalleşmeden dolayı daha ince ve eş eksenli taneler gözlemlenmiştir. Tüm kaynaklı yapılarda başarılı birleşmeler gerçekleşmiştir [18]. Bir diğer çalışmada SLE AlSi10Mg malzemenin sürtünme kaynak kabiliyeti araştırılmıştır. Kaynak işlemi sonucunda malzemede karıştırma bölgesi, termomekanik etkilenmiş bölge ve ana metal kısımları gözlemlenmiştir. Termomekanik etkilenmiş bölgede yetersiz deformasyondan ötürü yeniden kristalleşme ve tane irileşmesi oluşmamıştır. Ayrıca karıştırma bölgesinde tane incelmesine bağlı olarak sertlik miktarında artış tespit edilmiş̧ir [19]. SLE malzemeler basınçlı kaplar için de tercih edilmektedir. Nahmany ve diğerleri SLE AlSi10Mg malzemeyi elektron ışın kaynağ ile birleştirmişlerdir. Kaynaklı numunenin ortalama $30 \mathrm{MPa}$ civarında kabul edilebilir bir tutma basıncı sergilediği gözlemlenmiştir [20]. Katmanlı imalat tekniğiyle üretilen malzemelerin kaynak kabiliyetleri ile farklı üretim tekniğiyle imal edilen malzemelerin kaynak kabiliyetlerini kıyaslamak kaynak başarısını belirlemek için tercih 
edilen bir yöntemdir. SLE AlSi10Mg ve döküm yöntemiyle üretilen A356-T6 malzemeler elektron 1şın kaynağı ile birleştirilerek kıyaslanmıştır. SLE numunede önemsiz bir ısıdan etkilenen bölge belirlenmiş ve bu da kaynaklı yapının mekanik özelliklerinde beklenmeyen bir bozulmaya sebep olmuştur. A356T6 malzeme de ise kaynak metalinin bitişiğinde kısmen erimiş bölgenin varlığ gözlemlenmiş ancak belirli bir ısıdan etkilenen bölgenin varlığı tespit edilememiştir. SLE malzemenin sertlik değeri döküm malzemeye kıyasla daha yüksek gözlemlenmiştir [21]. Prashanth ve diğerleri SLE ile imal edilmiş Al12Si malzemenin sürtünme kaynağı sonrası mikroyapı ve mekanik özelliklerini araştırmışlardır. Ayrıca döküm tekniği ile imal edilen Al-12Si malzeme için de kıyaslama yapmışlardır. Kaynak prosesi sonrasında SLE ile döküm malzemeler arasında zıt bir sertlik dağılımı gözlenmiştir. SLE kaynaklı numunelerde önemli bir süneklik artışı tespit edilmiştir. Kaynaklı döküm numunelerde ise tam tersi bir durum belirlenmiştir. Bu durum Şekil 3'te verilmiştir. SLE kaynaklı bölgede Al matrisi içerisinde eşit dağılmış küçük Si parçacıkları gözlemlenmiş, ayrıca kaynak bölgesinde ana metale kıyasla daha küçük tane boyutu tespit edilmiştir [11].

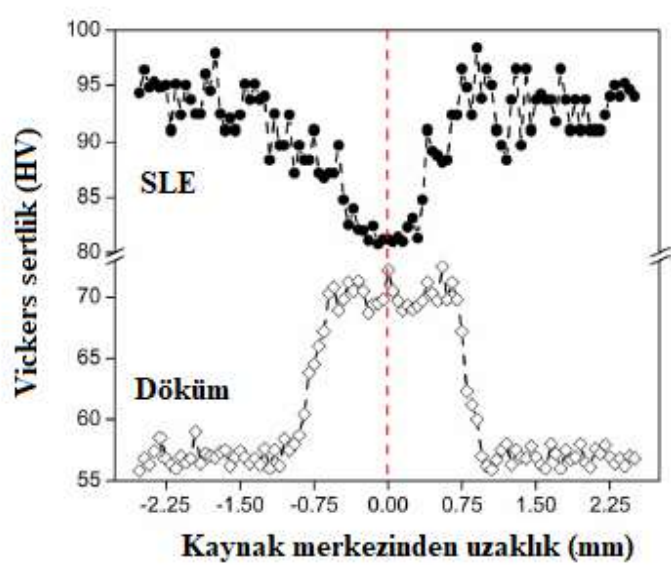

(a)

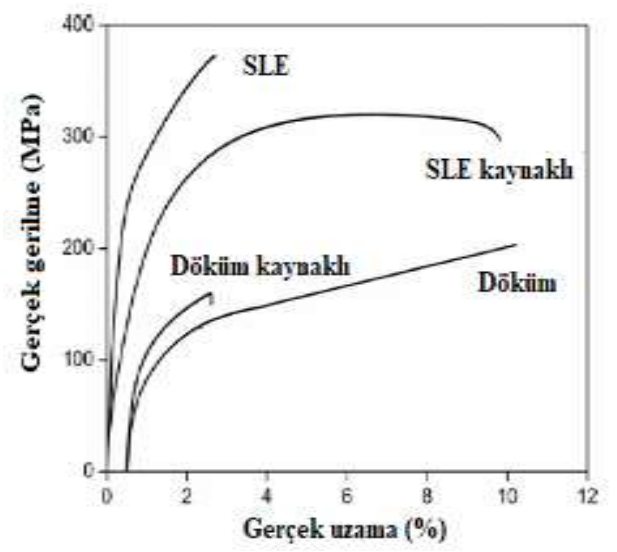

(b)

Şekil 3. Al-12Si kaynaklı malzemenin mekanik özellikleri; a) Sertlik dağılımı, b) Gerilme-uzama eğrisi [11]

Kaynaklı bağlantılarda farklı kaynak modları bağlantının sağlamlığını etkileyen parametreler arasında yer almaktadır. Kuryntsev yaptığ çalışmada SLE ile imal edilmiş PH1 paslanmaz çelik ile soğuk haddelenmiş 321 paslanmaz çeliği T-kaynak pozisyonunda lazer kaynağı ile birleştirmiştir. Çalışmada lazer kaynağında anahtar deliği modu ve isı iletim modunun kaynak yapısına etkisi araştırılmıştır. Ayrıca seçici lazer ergitme ile üretilen PH1 malzeme kaynak prosesinden önce 1sıl işleme tabi tutulmuştur. Şekil 4'te malzemelerin kaynak pozisyonu verilmiştir. Çalışma sonunda 1sı iletim modunda gerçekleştirilen kaynaklı yapının sertliğinin anahtar deliği moduna kıyasla daha yüksek olduğu tespit edilmiştir. Anahtar deliği modunda kaynak dikişleri çok daha büyük bir derinliğe ve daha büyük kaynak havuzuna sahiptir. Bundan dolayı kristalleşme hızı 1sı iletim modu ile kıyaslandığında daha az olmaktadır. Kaynaklı yapılarda ısıl işlem rejiminin bağlantı dayanımını etkilediği gözlemlenmiştir [22].

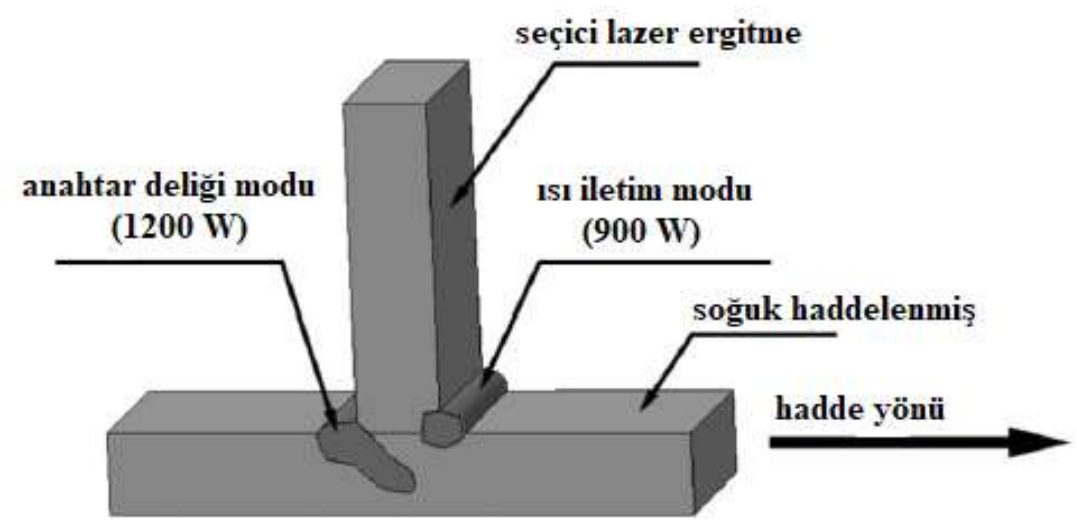

Şekil 4. SLE PH1 ve soğuk haddelenmiş 321 malzemenin kaynak şeması [22] 
Fieger ve diğerleri 316(SLE) - HSLA340(dövme) ve 18Ni-300(SLM) - 22MnB5(dövme) kombinasyonlarını lazer bindirme kaynağı ile birleştirmiş ve kesme kuvvetlerinin otomotiv sektörü için yeterliliğini araştırmışlardır. Kaynak kombinasyonu Tablo 2'de gösterilmiştir. Çalışma sonunda tüm numunelerin kaynağının başarıyla gerçekleştiği gözlemlenmiştir. Ayrıca $18 \mathrm{Ni}-300$ ve 22MnB5 kombinasyonunda $22 \mathrm{MnB} 5$ üstte olduğu durumda daha başarılı sonuçlar elde edildiği tespit edilmiştir [23].

Tablo 2. SLE ve dövme parçaların kaynak kombinasyonları [23]

\begin{tabular}{cccc}
\hline Üstteki plaka & Alttaki plaka & $\begin{array}{c}\text { Üstteki plakanın kalınlığı } \\
(\mathbf{m m})\end{array}$ & $\begin{array}{c}\text { Alttaki plakanın kalınlı̆̆ } \\
(\mathbf{m m})\end{array}$ \\
\hline HC340LA & HC340LA & 1 & 1 \\
316L & HC340LA & 1 & 1 \\
HC340LA & 316L & 1 & 1 \\
HC340LA & HC340LA & 2 & 2.5 \\
316L & HC340LA & 2 & 2.5 \\
HC340LA & 316L & 2.5 & 2 \\
22MnB5 & $22 M n B 5$ & 1 & 1 \\
18-Ni 300 & $22 M n B 5$ & 1 & 1 \\
22MnB5 & 18-Ni 300 & 1 & 1 \\
22MnB5 & $22 M n B 5$ & 2.3 & 2.3 \\
18-Ni 300 & $22 M n B 5$ & 2.3 & 2.3 \\
22MnB5 & $18-N i 300$ & 2.3 & 2.3 \\
\hline
\end{tabular}

Hibrit kaynak tekniği farkı iki kaynak yönteminin beraber kullanılarak birbirlerini desteklemesi suretiyle kaynak kalitesini arttıran bir prosestir [24]. Casalino ve diğerleri SLE ve geleneksel yöntemle imal edilen 316L malzemeyi lazer-ark hibrit kaynağı ile birleştirmişlerdir. Kaynaklı yapının mikroyapısında kaynak merkezi ve SLE tarafında sütun şeklinde tane yapıları gözlemlenmiştir. Ayrıca geleneksel yöntemle üretilen kısımda tane büyüklügünün SLE tarafına kıyasla daha büyük olduğu tespit edilmiştir. Çekme testlerinde dayanımın ana metale hemen hemen yakın olduğu ve kaynaklı yapının başarılı bir dayanım sergilediği gözlenmiştir. Ancak kaynaklı yapının düşük bir uzama gösterdiği de tespit edilmiştir [25].

SLE ile imal edilen malzemeler ergime sonrası hızlı soğumadan dolayı genellikle yüksek gerilme içermektedirler. $\mathrm{Bu}$ malzemeler ergitme kaynak yöntemleri ile birleştirildiği takdirde mikroyapıda ilave bir ek gerilme daha meydana gelmektedir. Bu sebepten dolayı katı hal kaynak yöntemi SLE parçaları için ilave ek gerilmelerden kaçınmak için tercih edilen bir kaynak tekniğidir [2632]. Parash ve diğerleri SLE Ti6Al4V parçaların sürtünme kaynağı sonrasında mikroyapı ve mekanik özelliklerini araştırmışlardır. SLE parça iç yapısında sadece $\alpha^{\prime}$ (martenzitik faz) gözlenirken kaynaklı SLE parçalarda hem $\alpha^{\prime}$ (martenzitik faz) hem de $\beta$ fazı gözlemlenmiştir. Kaynak bölgesinde oluşan $\alpha^{\prime}$ fazda boyut olarak daha ince ve eş eksenli bir yapı ortaya çımıştır. Şekil 5 'te kaynaklı numunenin optik mikroskop görüntüsü verilmiştir. Sertlik dağılımına bakıldığında kaynak bölgesinde sertlik artışı gözlemlenmiş ve bunun kaynak bölgesindeki ince $\alpha^{\prime}$ fazından kaynaklandığ 1 tespit edilmiştir. Ayrıca kaynaklı parçanın uzama değerinin SLE parçaya kıyasla \%60 daha fazla olduğu belirlenmiştir. Bunun yanında dayanımda az miktarda bir azalma gözlemlenmiştir. Sürtünme kaynă̆ının SLE parçaların önemli bir sorunu olan düşük sünekliği de iyileştirebileceği tespit edilmiş̧tir [33]. 

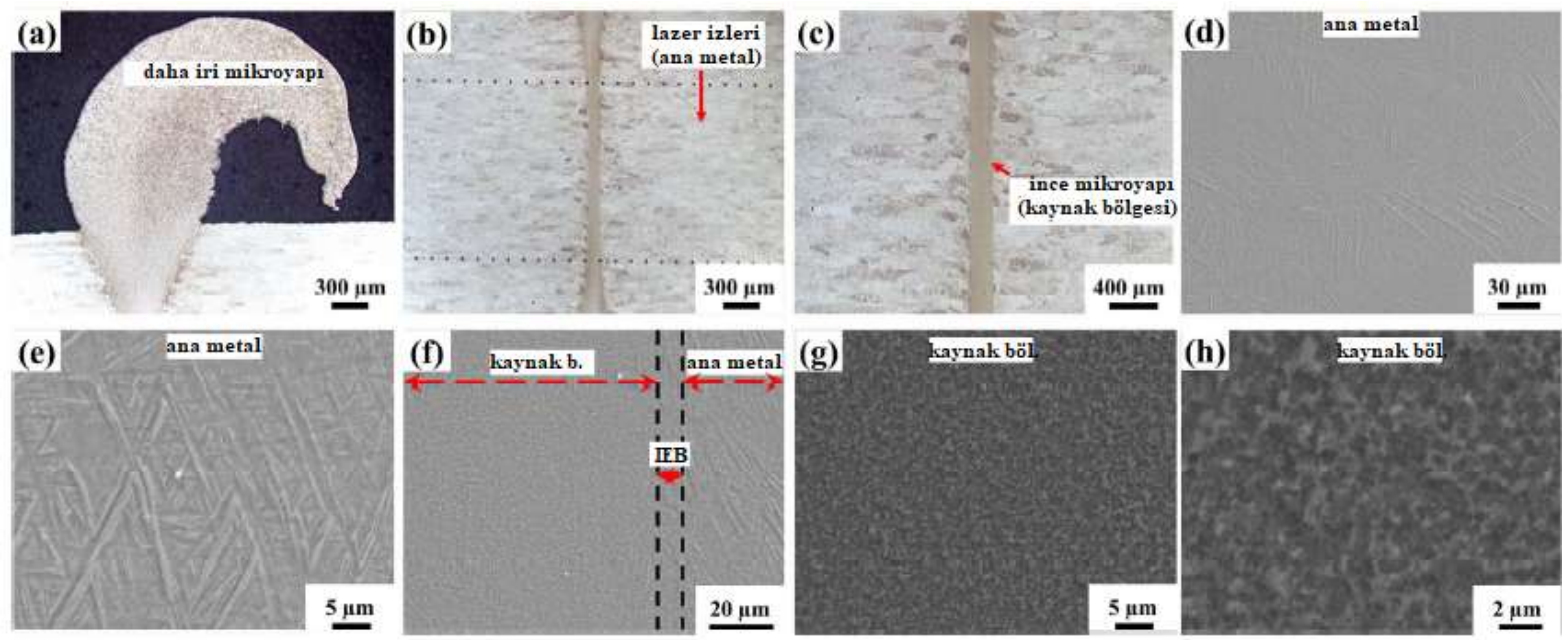

Şekil 5. Kaynaklı SLE Ti6Al4V numunelerin optik mikroskop görüntüsü; a) çapak, b,c) kaynaklı birleşim ve ana metal; Kall reaktifi ile 5-10 s aşındırma sonrası SEM görüntüsü; d,e) ana metal; f) ana metal, kaynak bölgesi ve ısıdan eetkilenen bölge (IEB); g,h) kaynak bölgesi [33]

SLE ile üretilen malzemeler anizotropik özellikler göstermekte bu durum da SLE malzemenin kaynak sonrası mikroyapı ve mekanik özelliklerinde farklılığa sebep olmaktadır [34]. Chen ve diğerleri SLE ile üretilen Ti-6.5Al-3.5Mo-1.5Zr-0.3Si titanyum alaşımını inşa yönü (IY) ve enine yön (EY) olarak elektron ışın kaynağı ile birleştirmişlerdir. SLE ile üretilen plakanın şematik gösterimi Şekil 6' da verilmiştir. Kaynaklı bölgede hızlı soğumadan dolayı iğnemsi a' fazının oluştuğu tespit edilmiştir. Kaynaklı bölgenin derinliği arttıkça, daha iğnemsi $\alpha^{\prime}$ fazının meydana geldiği belirlenmiştir. Kaynaklı bölgede $\alpha^{\prime}$ fazı oluşumundan dolayı sertlik değerinin 1sıdan etkilenen bölge ve ana metale kıyasla daha yüksek olduğu gözlemlenmiştir. Mekanik test sonuçlarına bakıldığında İY kaynaklı numunelerin dayanımı EY kaynaklı numunelere kıyasla daha yüksek tespit edilmiş ancak EY kaynaklı numunelerin sünekliğinin IIY kaynaklı numunelere göre daha fazla olduğu gözlemlenmiştir [35].

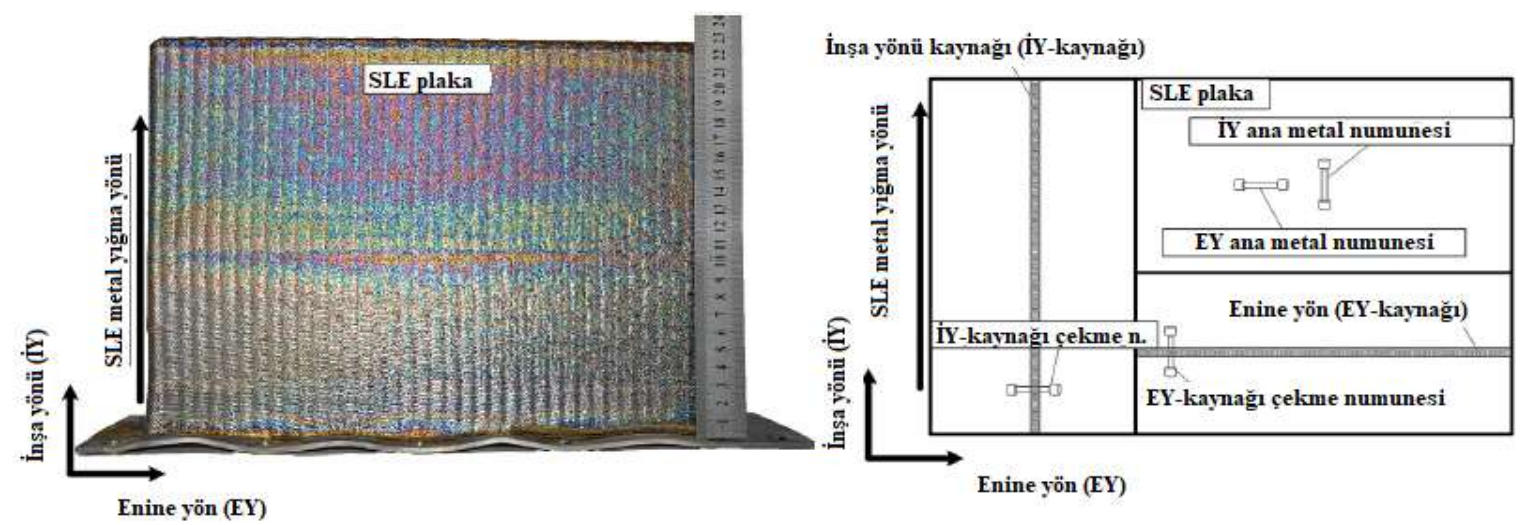

Şekil 6. SLE ile üretilmiş plakanın şematik gösterimi [35]

Nikel bazlı süper alaşımların yapısal özelliklerinden dolayı yüksek sıcaklıkta çalışma performansları oldukça yüksektir. Hu ve diğerleri SLE Inconel625 malzemenin lazer kaynağı sonrasında yüksek sıcaklıkta mekanik özelliklerini araştırmışlardır. Kaynak bölgesinde ana metale kıyasla sütunlu bir yapı gözlemlenmiştir. Bu durum Şekil 7'de gösterilmiştir. Bu durumdan dolayı kaynak bölgesinde ana metale kıyasla daha düşük sertlik değeri tespit edilmiştir. Kaynaklı numunelere $815^{\circ} \mathrm{C}$ 'da çekme testleri yapılmış ve kopmalar ana metal bölgesinde gerçekleşmiştir. Bu durum lazer kaynağının SLE Inconel625 malzeme için başarıyla uygulanabileceğini kanıtlamaktadır [36]. 


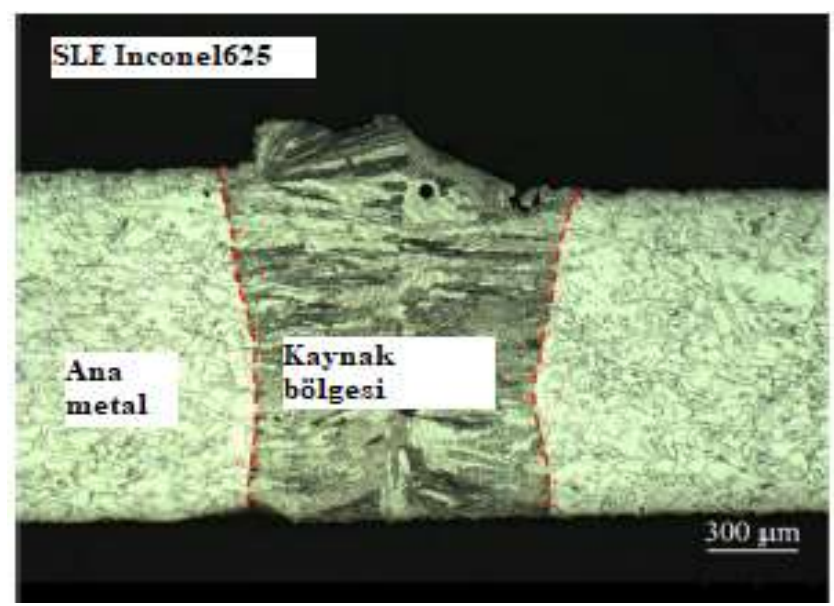

Şekil 7. Lazer kaynaklı SLE Inconel 625'in optik mikroskop görüntüsü [36]

\subsection{Elektron Işını ile Üretilen Malzemelerin Kaynağı}

Elektron 1şını ergitme (EIE) yöntemi, toz halinde bulunan metalleri elektron 1şını vasıtasıyla ergitme ve birleştirme prosesi olarak tanımlanmaktadır [37]. Elektron 1şını, her bir katmanı kullanılan malzemeye özgü optimum bir ortam sıcaklığına kadar 1sıtır. Bundan dolayı EIE ile üretilen parçalarda artık gerilme oluşmamakta ve dolayısıyla martenzitik yapılar bulunmamaktadır [13]. EIE prosesinde odaklanmış elektron ışını ince toz tabakasını taramakta ve belirli bir enine kesit alan üzerine lokal ergitme yaparak katılaşmayı sağlamaktadır. EIE yönteminde toz boyutu ve katman kalınlığı daha büyüktür. Buna karşın EIE yöntemiyle imal edilen parçaların yüzey kalitesi daha düşük olmaktadır [38]. Şekil 8'de elektron 1şın ergitme şema görüntüsü verilmiştir [39].

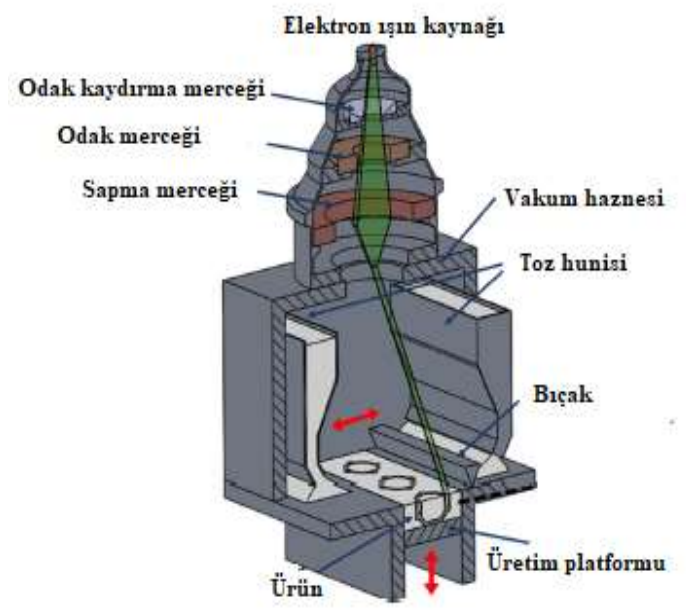

Şekil 8. EIE yönteminin şematik gösterimi [39]

Sürtünme karıştırma kaynağında ilerleme hızı kaynaklı yapının mikroyapı ve mekanik özelliklerini etkileyen önemli parametreler arasında yer almaktadır. Rubino ve diğerleri EIE Ti6Al4V malzemenin sürtünme karıştırma kaynağında düşük, orta ve yüksek ilerleme hızının kaynak kalitesine etkisini araştırmışlardır. Orta ilerleme hızında yüzey kalitesinin önemli bir gelişme gösterdiği belirlenmiştir. İlerleme hızının ise sertlik dağılımı üzerinde önemli bir etkisi olmadığı anlaşılmıştır. Ayrıca kaynaklı yapının karıştırma bölgesinde rekristalizasyondan dolayı mikroyapıda incelme oluşmuş ve bunun sonucunda eş eksenli tanecikler tespit edilmiştir. Bu durumdan dolayı karıştırma bölgesinde sertlik değeri daha yüksek belirlenmiştir. Sürtünme karıştırma kaynağının parça gözenekliğini azalttığı gözlemlenmiştir [39]. Sun ve diğerleri EIE Ti6Al4V ve dövme plakaları lazer kaynağı ile birleştirmişlerdir. Çalışmada EIE inşa yönü ve kaynak dikişi arasındaki kaynak açısı değeri 0, 30, 45 derece olarak tercih edilmiştir. Kaynak pozisyonu Şekil 9'da verilmiştir. Kaynaklı bölge mikroyapısında kaynak dikişine doğru yönlenmiş sütunlu yapıda $\beta$ tanecikleri gözlemlenmiştir. Hızlı katılaşmadan 
dolayı $\beta$ tanelerinde ortogonal olarak yönlenmiş a' (martenzit) gözlemlenmiştir. Kaynak bölgesinin EIE tarafındaki $\beta$ taneciklerinin genişliği dövme tarafına kıyasla daha büyük tespit edilmiştir. Kaynak açısının dayanım üzerinde belirli bir etkisi olmadığı anlaşılmış ancak kaynak açısının artmasıyla sünekliğin azaldığ gözlemlenmiştir. Ayrıca kaynak bölgesinin sertliğinin hem EIE hem de dövme tarafina kıyasla daha yüksek olduğu tespit edilmiştir [40].
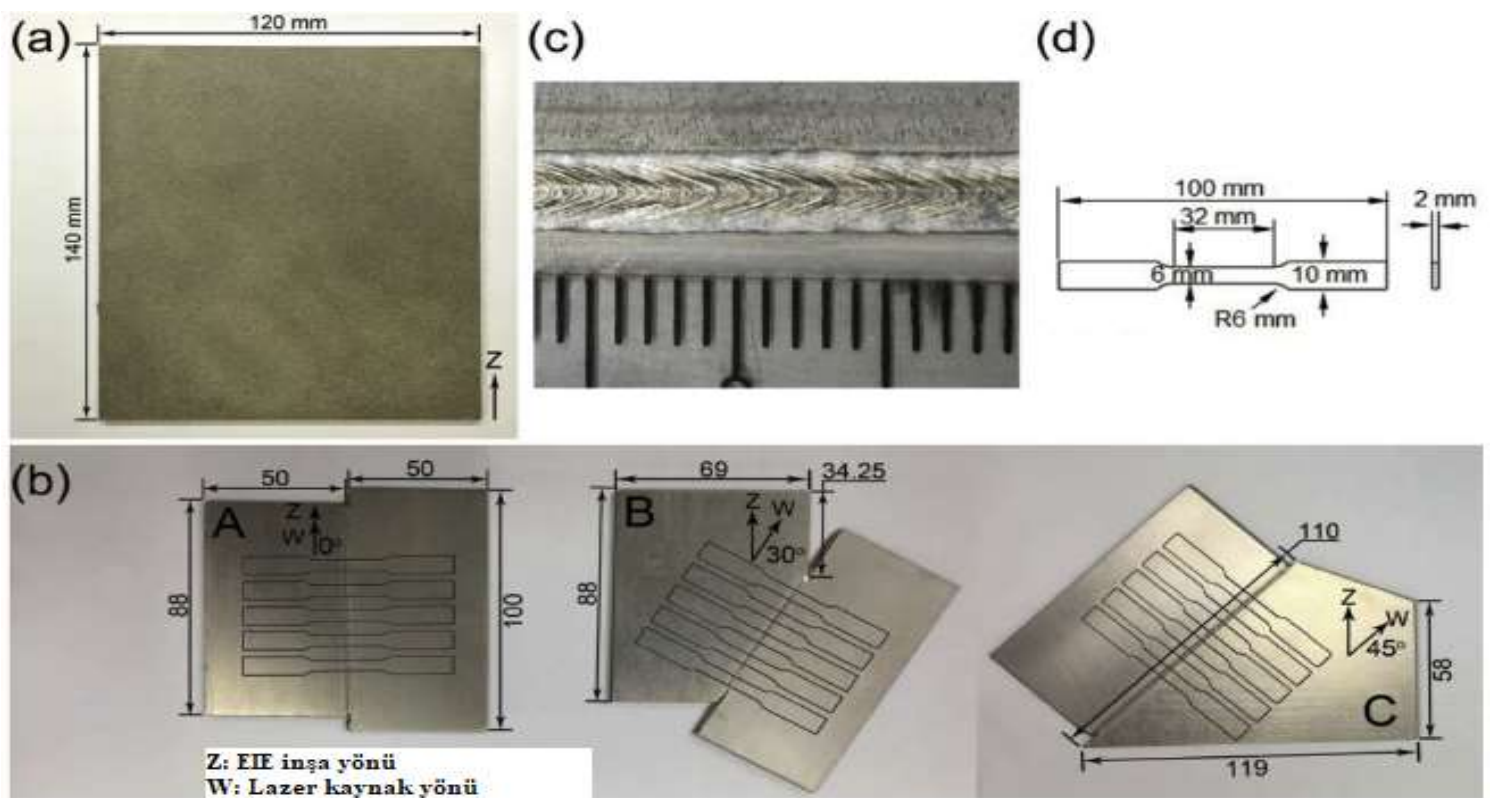

Şekil 9. EIE-dövme parçaların kaynağı; a) $120 \mathrm{~mm}$ x 5 mm x $130 \mathrm{~mm}$ boyutunda olan EIE yapılı Ti-6Al-4V plakanın resmi, b) lazer kaynağı sırasında EIE yapımı parçaların ve dövme plakaların yerleştirilmesi, c) kaynak yerinin yüzey görünümü, d) çekme numunelerinin boyutu [40]

Scherillo ve diğerleri yaptıkları çalışmada EIE Ti6Al4V malzemeyi lineer sürtünme kaynağı ile birleştirmişlerdir. Kaynak prosesi sonucunda kaynak bölgesi, termomekanik etkilenmiş bölge ve ana metal kısımları gözlemlenirken 1sıdan etkilenen bölgenin varlığı tespit edilememiştir. Kaynak bölgesinin ana metale kıyasla daha ince taneli olduğu ve kaynak bölgesinde herhangi bir gözenekli yapının bulunmadığı belirlenmiștir. Sertlik dağılımında ise bölgeler arasında anlamlı bir değişiklik gözlenmemiştir [41]. Katmanlı imalat ile üretilen malzemelerde artık gerilmelerin oluşması malzemenin mekanik özelliklerini önemli ölçüde azaltmaktadır. Bu problemi aşmak için katmanlı imalat ile üretilen metalik malzemelere 1 sıl işlem prosesi uygulanmaktadır. Sankar ve diğerleri EIE Ti-48Al-2Cr-2Nb malzemeyi sürtünme kaynağ ile birleştirmiştir. Malzemeye, kaynak öncesi ve sonrasında 1sıl işlem uygulanmıştır. Çalışma sonunda kaynak öncesi ısıl işlem görmüş ve hiç ısıl işlem görmemiş parçaların kopmasının kaynak bölgesinde gerçekleştiği tespit edilmiştir. Kaynak sonrası 1sıl işlem uygulanan parçalar ise yüksek mekanik özellikler göstermiştir. Ayrıca kaynak sonrası 1sıl işlem uygulanan parçaların kaynak bölgesinin homojen bir yapıya sahip olduğu gözlemlenmiştir. Bu sonuçlar EIE parçalarda kaynak öncesi ısıl işlem uygulamanın gerekli olmadığını göstermektedir [42].

EIE ile orta ve yüksek büyüklükte parça üretiminde uzun tarama mesafesi enerji yoğunluğunun azalmasına sebep olmaktadır. Bu durum EIE parçalarının mekanik özelliklerini önemli ölçüde azaltmaktadır. Bu problemi aşmak için Wang ve diğerleri yerinde kaynak profilini kullanmak suretiyle EIE ile üretilen küçük parçaları imalat aşamasında birleştirmişlerdir. Kaynak şeması Şekil 10'da verilmiştir. Kaynak prosesi sonrasında birleştirilen malzemenin mikroyap1 ve mekanik özellikleri araştırılmıştır. Kaynaklı bölgenin mikroyapısında az miktarda gözenekli kısım tespit edilmiştir. Ana metal ile kaynaklı numunelerin mikrosertlik ve çekme testleri sonuçlarının benzerlik gösterdiği belirlenmiştir. Bu durum yerinde kaynak yönteminin EIE orta ve büyük boyutlu parçaların üretiminde güvenle tercih edilebileceğini ispatlamaktadır [43]. 


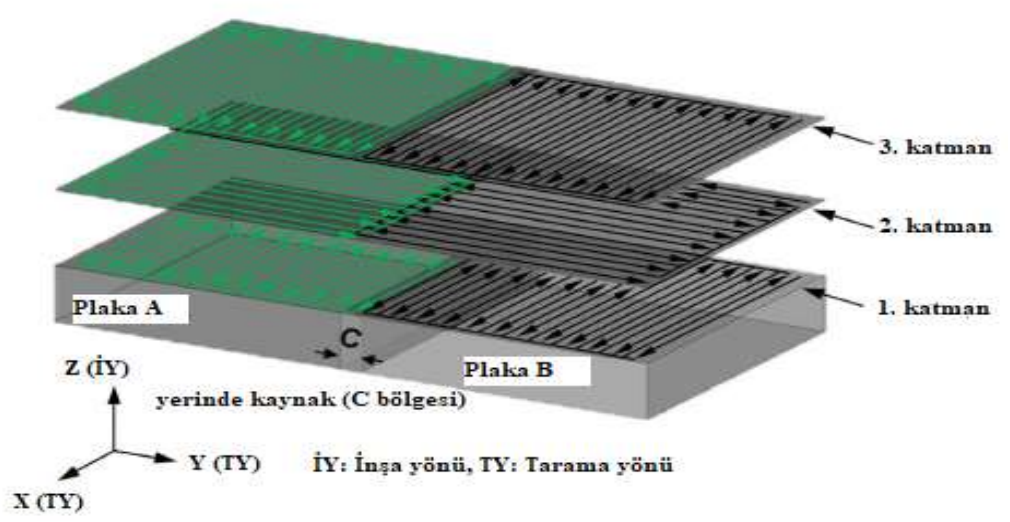

Şekil 10. EIE Ti6Al4V malzemenin yerinde kaynak şeması [43]

\section{Sonuç ve Öneriler}

SLE ve EIE ile üretilen malzemelerin kaynağının optimum parametreler sağlandığı takdirde başarılı birleştirme sonuçları verdiği tespit edilmiştir. Çalışma sonunda elde edilen genel sonuçlar aşağıda verilmiştir;

- Kİ yönteminin dezavantajlarından biri olan gözenekli yapı probleminin kaynaklı birleştirmeler ile azaltılabileceği anlaşılmıştır.

- Özellikle katı hal sürtünme kaynağının Kİ malzemelerde düşük sünekliği arttırabileceği gözlemlenmiş ve \%60 seviyelerine kadar uzamayı arttıcı etkide bulunduğu belirlenmiştir.

- Kİ malzemelerde önce ergitme daha sonra hızlı soğumadan dolayı artık gerilmeler meydana gelmektedir. Kaynak prosesi olarak katı hal kaynak yöntemleri tercih edildiği takdirde malzeme yapısında ilave artık gerilmeler oluşmayacağı gözlemlenmiştir.

- SLE ve EIE malzemeler anizotropik özellik göstermektedir. Bu durum kaynak prosesi sonrasında yöne bağlı olarak mikroyapı ve mekanik özelliklerde farklılık oluşturmaktadır.

- EIE ile orta ve yüksek büyüklükte parça üretiminde uzun tarama mesafesi enerji yoğunluğunun azalmasına sebep olmaktadır. Bu durum EIE parçalarının mekanik özelliklerini önemli ölçüde azaltmaktadır. Yerinde kaynak yöntemiyle bu sorun ortadan kaldırılabilmektedir.

- SLE ve EIE parçalara kaynak prosesi sonrasında 1sıl işlem uygulanması kaynaklı yapının mikroyapı ve mekanik özelliklerini arttırıcı etkide bulunmaktadır.

- Çalışma sonunda Kİ teknolojisinin yeni ve gelişmekte olan bir üretim tekniği olduğundan bu yöntemle üretilen malzemelerin kaynak çalışmalarının sınırlı seviyede bulunduğu anlaşılmaktadır. Araştırmacıların bu konuda farklı kaynak yöntemi ve farklı malzemeleri tercih ederek çeşitli çalışmalar yapabilecekleri ve literatüre katkı sağlayabilecekleri düşünülmektedir.

\section{Kaynaklar}

[1] Aktimur B., Gökpınar E.S. 2015. Katmanlı Üretimin Havacılıkdaki Uygulamaları. Gazi Üniversitesi Fen Bilimleri Dergisi Part: C, 3 (2): 463-469.

[2] Ayan Y., Kahraman N. 2018. Metal Eklemeli İmalat: Tel Ark Yöntemi ve Uygulamaları. International Journal of 3D Printing Technologies and Digital Industry, 2 (3): 74-84.

[3] Ding D., Pan Z. S., Cuiuri D., Li H. 2014. A Tool-Path Generation Strategy for Wire and Arc Additive Manufacturing. The International Journal of Advanced Manufacturing Technology, 73 (2014): 173-183.

[4] Turhan S., Özsoy A. 2016. DMLS Yöntemiyle İmal Edilen Ti6A14V Alaşım Özelliklerine İşlem Parametrelerinin Etkisi. SDU International Journal of Technological Science, 8 (2): 15-27.

[5] Calignano F., Mandfredi D., Ambrosio E.P., Luliano L., Fino P. 2013. Influence of Process Parameters on Surface Roughness of Aluminum Parts Produced by DMLS. Int. J Adv Manufacturing Technology, 67 (2013): 2743-2751. 
[6] Ponche R., Kerbrat O., Mognol P., Hascoet J.Y. 2014. A Novel Methodology of Design for Additive Manufacturing Applied to Additive Laser Manufacturing Process. Robotics and Computer-Integrated Manufacturing, 30 (4): 389-398.

[7] Liberini M., Astarita A., Campatelli G., Scippa A., Montevecchi F., Venturini G., Durante M., Boccarusso L., Memola F., Minutolo C., Squillace A. 2017. Selection of Optimal Process Parameters for Wire Arc Additive Manufacturing. 10th CIRP Conference on Intelligent Computation in Manufacturing Engineering - CIRP ICME '16, pp: 470-474, 20-22 July 2016, Ischia, Italy.

[8] Fang X., Zhang L., Li H., Li C., Huang K., Lu B. 2018. Microstructure Evolution and Mechanical Behavior of 2219 Aluminum Alloys Additively Fabricated by the Cold Metal Transfer Process. Materials, 11 (2018): 812-824.

[9] Ge J., Lin J., Lei Y., Fu H. 2018. Location-Related Thermal History, Microstructure, and Mechanical Properties of Arc Additively Manufactured 2Cr13 Steel Using Cold Metal Transfer Welding. Materials Science \& Engineering A, 715 (2018): 144-153.

[10] Hopkinson N., Hauge R., Dickens P. 2005. Rapid Manufacturing:An Industrial Revolution for the Digital Age. Edited by Wiley., Loughborough University, UK, 55-81.

[11] Prashanth K.G., Damodaram R., Scudino S., Wang Z., Rao K.P., Eckert J. 2014. Friction Welding of Al-12Si Parts Produced by Selective Laser Melting. Materials \& Design, 57 (2014): 632-637.

[12] Çelik İ., Karakoç F., Çakır M.C., Duysak A. 2013. Hızlı Prototipleme Teknolojileri Ve Uygulama Alanlar1. Dumlupınar Üniversitesi Fen Bilimleri Enstitüsü Dergisi, 31 (2013): 53-70.

[13] Introductıon to Additive Manufacturıng Technology 2015. http://eklemeliimalat.info.tr/ (Erişim Tarihi: 08.03.2019).

[14] Thijs L., Kempen K., Kruth J.P., Van Humbeeck J. 2013. Fine-Structured Aluminium Products with Controllable Texture by Selective Laser Melting of Pre-Alloyed AlSi10Mg Powder. Acta Materialia, 61 (5): 1809-1819.

[15] Prashanth K. G., Scudino S., Klauss H.J., Surreddi K.B., Löber L., Wang Z., Eckert J. 2014. Microstructure and mechanical properties of $\mathrm{Al}-12 \mathrm{Si}$ produced by selective laser melting: Effect of heat treatment. Materials Science and Engineering: A, 590 (2014): 153-160.

[16] Scudino S., Unterdörfer C., Prashanth K.G., Attar H., Ellendt N., Uhlenwinkel V., Eckert J. 2015. Additive Manufacturing of $\mathrm{Cu}-10 \mathrm{Sn}$ Bronze. Materials Letters, 156 (2015): 202-204.

[17] Magalhaes E., Limae Silva A., Limae Silva S. 2017. A GTA Welding Cooling Rate Analysis on Stainless Steel and Aluminum Using Inverse Problems. Applied Sciences, 7 (2): 122-137.

[18] Du Z., Chen H., Tan M.J., Bi G., Chua C.K. 2018. Investigation of Porosity Reduction, Microstructure and Mechanical Properties for Joining of Selective Laser Melting Fabricated Aluminium Composite via Friction Stir Welding. Journal Of Manufacturing Processes, 36 (2018): 33-44.

[19] Scherillo F., Astarita A., Prisco U., Contaldi V., Di Petta P., Langella A., Squillace A. 2018. Friction Stir Welding of AlSi10Mg Plates Produced by Selective Laser Melting. Metallography, Microstructure, and Analysis, 7 (4): 457-463.

[20] Nahmany M., Stern A., Aghion E., Frage N. 2017. Structural Properties of EB-Welded AlSi10Mg Thin-Walled Pressure Vessels Produced by AM-SLM Technology. Journal of Materials Engineering and Performance, 26 (10): 4813-4821.

[21] Nahmany M., Rosenthal I., Benishti I., Frage N., Stern A. 2015. Electron Beam Welding of AlSi10Mg Workpieces Produced by Selected Laser Melting Additive Manufacturing Technology, Additive Manufacturing, 8 (2015): 63-70.

[22] Kuryntsev S.V. 2018. The Influence of Pre-heat Treatment on Laser Welding of T-joints of Workpieces Made of Selective Laser Melting Steel and Cold Rolled Stainless Steel, Optics \& Laser Technology, 107 (2018): 59-66.

[23] Fieger T.V., Sattler M.F., Witt G. 2018. Developing Laser Beam Welding Parameters for The Assembly of Steel SLM Parts for The Automotive Industry. Rapid Prototyping Journal, 24 (8): 1288-1295.

[24] Yavuz H., Çam G. 2005. Lazer-Ark Hibrit Kaynak Yöntemi. Mühendis ve Makine Dergisi, 46 (543): 14-19. 
[25] Casalino G., Campanelli S.L., Ludovico A.D. 2013. Laser-Arc Hybrid Welding of Wrought to Selective Laser Molten Stainless Steel. The International Journal of Advanced Manufacturing Technology, 68 (1-4): 209-216.

[26] Vora P., Mumtaz K., Todd I., Hopkinson N. 2015. Alsi12 İn-Situ Alloy Formation and Residual Stress Reduction Using Anchorless Selective Laser Melting. Additive Manufacturing, 7 (2015): $12-19$

[27] Trevisan F., Calignano F., Lorusso M., Pakkanen J., Aversa A., Ambrosio E., Manfredi D. 2017. On The Selective Laser Melting (SLM) of The AlSi10Mg Alloy: Process, Microstructure, and Mechanical Properties, Materials, 10 (1): 76-87.

[28] Liu Y., Yang Y., Wang D. 2016. A Study on The Residual Stress During Selective Laser Melting (SLM) of Metallic Powder. The International Journal of Advanced Manufacturing Technology, 87 (1-4): 647-656.

[29] Mercelis P., Kruth J. P. 2006. Residual Stresses in Selective Laser Sintering and Selective Laser Melting. Rapid Prototyping Journal, 12 (5): 254-265.

[30] Kouadri-Henni A., Seang C., Malard B., Klosek V. 2017. Residual Stresses Induced by Laser Welding Process in The Case of A Dual-Phase Steel DP600: Simulation and Experimental Approaches. Materials \& Design, 123 (2017): 89-102.

[31] Bajpei T., Chelladurai H., Ansari M.Z. 2017. Experimental Investigation and Numerical Analyses of Residual Stresses and Distortions In GMA Welding of Thin Dissimilar AA5052-AA6061 Plates. Journal of Manufacturing Processes, 25 (2017): 340-350.

[32] Fu G., Lourenço M.I., Duan M., Estefen S.F. 2016. Influence of The Welding Sequence on Residual Stress and Distortion of Fillet Welded Structures. Marine Structures, 46 (2016): 30-55.

[33] Prashanth K.G., Damodaram R., Maity T., Wang P., Eckert J. 2017. Friction Welding of Selective Laser Melted Ti6Al4V Parts. Materials Science and Engineering: A, 704 (2017): 66-71.

[34] Liu C.M., Tian X.J., Tang H.B., Wang H.M. 2013. Microstructural Characterization of Laser Melting Deposited Ti-5Al-5Mo-5V-1Cr-1Fe Near $\beta$ Titanium Alloy. Journal of Alloys and Compounds, 572 (2013): 17-24.

[35] Chen X., Zhang J., Chen X., Cheng X., Huang Z. 2018. Electron Beam Welding of Laser Additive Manufacturing Ti-6.5 Al-3.5 Mo-1.5 Zr-0.3 Si Titanium Alloy Thick Plate. Vacuum, 151 (2018): 116-121.

[36] Hu X., Xue Z., Zhao G., Yun J., Shi D., Yang X. 2019. Laser Welding of A Selective Laser Melted Ni-Base Superalloy: Microstructure and High Temperature Mechanical Property. Materials Science and Engineering: A, 745 (2019): 335-345.

[37] Özsoy K., Duman B. 2017. Eklemeli İmalat (3 Boyutlu Baskı) Teknolojilerinin Eğitimde Kullanılabilirliği. International Journal of 3d Printing Technologies and Digital Industry, 1 (1): 36-48.

[38] Yalçın B., Ergene B. 2017. Endüstride Yeni Eğilim Olan 3-D Eklemeli İmalat Yöntemi ve Metalurjisi. Süleyman Demirel Üniversitesi Uluslarası Teknolojik Bilimler Dergisi, 9 (3): 65-88.

[39] Rubino F., Scherillo F., Franchitti S., Squillace A., Astarita A., Carlone P. 2019. Microstructure and Surface Analysis of Friction Stir Processed Ti-6Al-4V Plates Manufactured by Electron Beam Melting. Journal of Manufacturing Processes, 37 (2019): 392-401.

[40] Sun Y.Y., Wang P., Lu S.L., Li L.Q., Nai M.L.S., Wei J. 2019. Laser Welding of Electron Beam Melted Ti-6Al-4V To Wrought Ti-6Al-4V: Effect of Welding Angle on Microstructure and Mechanical Properties. Journal of Alloys and Compounds, 782 (2019): 967-972.

[41] Scherillo F., Astarita A., Carrino L., Pirozzi C., Prisco U., Squillace A. 2019. Linear Friction Welding of Ti-6Al-4V Parts Produced by Electron Beam Melting, Materials and Manufacturing Processes, 34 (2): 201-207.

[42] Sankar G.S., Karthik G.M., Mohammad A., Kumar R., Ram G.J. 2019. Friction Welding of Electron Beam Melted $\gamma$-TiAl Alloy $\mathrm{Ti}-48 \mathrm{Al}-2 \mathrm{Cr}-2 \mathrm{Nb}$. Transactions of the Indian Institute of Metals, 72 (1): 35-46.

[43] Wang P., Nai M.L.S., Sin W.J., Lu S., Zhang B., Bai J., Wei J. 2018. Realizing A Full Volume Component by In-Situ Welding During Electron Beam Melting Process. Additive Manufacturing, 22 (2018): 375-380. 